\title{
Transmission intensity and malaria vector population structure in Magugu, Babati District in northern Tanzania
}

\author{
CHARLES E. MWANZIVA ${ }^{1 *}$, JOVIN KITAU ${ }^{1}$, PATRICK K. TUNGU ${ }^{2}$, CLEMENT N. MWEYA ${ }^{3}$, \\ HUMPHREY MKALI ${ }^{1}, \mathrm{CHACHA} \mathrm{M}$. NDEGE ${ }^{4}$, ALEX SANGA ${ }^{5}, \mathrm{CHARLES} \mathrm{MTABHO}^{1} \mathrm{CHARLES}$ \\ LUKWARO $^{1}$, SALUM AZIZI ${ }^{6}$, JOSEPH MYAMBA ${ }^{2}$, JAFFU CHILONGOLA ${ }^{1}$, STEPHEN M. \\ MAGESA $^{2}$, SEIF SHEKALAGHE ${ }^{1}$ and FRANKLIN W. MOSHA ${ }^{1}$ \\ ${ }^{1}$ Kilimanjaro Christian Research Institute, P. O. Box 2236, Moshi, Tanzania \\ ${ }^{2}$ National Institute for Medical Research, Muheza, Tanzania \\ ${ }^{3}$ National Institute for Medical Research, Tukuyu, Tanzania \\ ${ }^{4}$ National Institute for Medical Research, Mwanza, Tanzania \\ ${ }^{5}$ St. John University of Tanzania, Dodoma, Tanzania \\ ${ }^{6}$ Ifakara Health Institute, Ifakara, Tanzania
}

\begin{abstract}
A 1-year longitudinal study was conducted in Magugu in Babati district, northern Tanzania to determine malaria vector population structure and malaria transmission indices. Mosquitoes were sampled using the Centre for Disease Control (CDC) light traps. A total of 110,357 adult female mosquitoes were collected. Anopheles gambiae s.l. accounted 25\% of the total female mosquito collected. Relatively fewer An. funestus were collected. Other mosquito species collected were An. pharoensis, An. coustani, An. maculipalpis, An. marshallii, Culex quinquefasciatus, Cx unnivittatus, Mansonia uniformis and Ma. africana. An analysis by Polymerase Chain Reaction revealed that $A n$. arabiensis was the only member of the An. gambiae complex in the collected samples. The number of mosquito collected correlated with the increasing mean rainfall. Blood meal analysis showed a higher human enzymatic reaction among An. gambiae s.l. (63.5\%) followed by An. funestus (42.9\%). Bovine enzymatic reaction was higher among An. coustani (73.7\%) followed by the An. pharoensis (66.7\%). The Enzyme Linked Immunosorbent Assay (ELISA) was used to detect Plasmodium falciparum circumsporozoites proteins in 10,000 female Anopheles mosquitoes. Only two An. arabiensis were found to be infected. The entomological inoculation rate (EIR) was estimated at 0.51 infectious bites per person per year. This EIR was considered to be relatively low, indicating that malaria transmission in this area is low. Variability in mosquito blood meal shows availability of variety of preferred blood meal choices and impact of other factors inhibiting mosquito-human host contact. The study has provided information considered useful in the mapping of the vector distribution and population structure in the country. Such information is considered to be among the essential tools for planning malaria control interventions.
\end{abstract}

Keywords: Anopheles arabiensis, malaria, transmission, vector abundance, Tanzania

\section{Introduction}

Malaria is one of the most significant infectious diseases in the world. Available statistics suggest that 2 to $5 \%$ of all human deaths in the $20^{\text {th }}$ Century were attributed to the disease (Carter et al., 2002), and increasing evidence identifies malaria as the most significant recent selective pressure on the human genome (Kwiatkowski, 2005). In 2000, 20\% of all deaths of children under 5 years in Sub-Saharan Africa were attributable to malaria (Black et al., 2003; WHO, 2006). In Tanzania, 18 million clinical malaria cases annually result in approximately 80,000 deaths (MoHSW, 2008).

\footnotetext{
* Correspondence: Dr. Charles Mwanziva; Email: cmwanziva@yahoo.com
} 
Most malaria cases in Tanzania are due to Plasmodium falciparum (Mboera, 2000). $P$. falciparum is transmitted by female anopheles mosquitoes during a blood meal. Gillies \& Meillon (1968) defined 11 out of the 45 anopheline mosquito species as responsible vectors for malaria transmission in Tanzania. The most important malaria vectors in Tanzania include Anopheles gambiae s.s., An. arabiensis and An. merus (Mnzava \& Kilama, 1986; Shiff et al., 1995; Kigadye et al., 2010) and An. funestus (White, 1974; Mboera et al., 1997, 2010; Van Rensburg et al., 1996). An. rivulorum and An. marshallii have also been identified as vectors of malaria in north-eastern Tanzania (Magesa et al., 1991; Wilkes et al., 1996; Malima, 1999).

A measure of entomological inoculation rates (EIR) is an important tool for estimation of malaria transmission intensity (Drakeley et al., 2003). It is one of the indicators of human exposure to malaria parasites (Killeen et al., 2000). In Tanzania, EIR has been shown to vary with season, altitude, proximity to breeding sites, socio-economic status, agro-ecological systems (Ijumba et al., 2002; Kulkarni et al., 2006; Mboera et al., 2010). The enormous heterogeneity in malaria transmission intensity in Tanzania calls for targeted malaria control operations that require an understanding of the forces that drive transmission (Mboera et al., 2010). The knowledge on malaria transmission indices is important to its control through quantifying the potential risk of infection (Githeko et al., 1993). This calls for the need to accurately determine the mosquito population structure, spatial and temporal variations in malaria transmission within localized areas that will target specific needs in malaria interventions. This study was therefore carried out to determine mosquito population structure, its temporal variation and transmission indices in Magugu area of Babati District in northern Tanzania.

\section{Materials and methods}

\section{Study site}

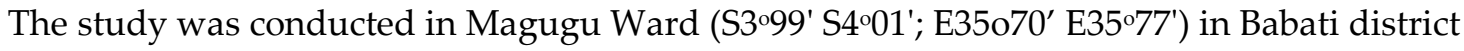
of northern Tanzania. The area lies along the northern eastern arm of the Tanzanian Rift Valley at an altitude of $900-1600 \mathrm{~m}$. Magugu receives an annual average rainfall of $650 \mathrm{~mm}$ distributed in two seasons; short rains from October to December and long rains from March to May. Magugu Ward has seven villages and a total population of 26,131 people. The study was carried out in Gichameda village. The village is made up of four subvillages, namely Gichameda A, Gichameda B, Kinambichi and Madibira. The main economic activities include crop agriculture and livestock keeping.

\section{Adult mosquito collection and identification}

The four sub villages, Gichameda A and B, Kinambichi and Madibira were selected for adult mosquitoes sampling. Adult mosquitoes were collected indoors using the Centre for Disease Control (CDC) light traps (J.W. Hock Ltd, Gainesville, Florida, USA), from the randomly selected houses. The traps were suspended at the foot end of the bed about a meter above the bed level (Mboera et al., 1998). These traps were set from $1900 \mathrm{hr}$ and retrieved at $0700 \mathrm{hr}$ ). Five rounds of mosquito collections were made in 2008-2009; one in November/December 2008 (representing the short rainy season), February/March (at the start of long rainy season), May (just after the long rainy season), July/August 2009 (dry season) and in October 2009 (at the end of dry season). Mosquitoes collected were sorted by species, sex and physiological state using morphological characteristics (Gillies \& Coetzee, 1987; Gillies \& De Meillon, 1968). 
A small proportion of An. gambiae complex was preserved in a refrigerator at $-20^{\circ} \mathrm{C}$ prior to further identification by Polymerase Chain Reaction (PCR) (Scott et al., 1993). Based on the sequence of nucleotide amplified, An. arabiensis with 315bp, An. gambiae s.s with 390bp DNA fragments were processed. Blood meal source analysis from mosquitoes was determined using the method described by Bray et al. (1984).

\section{Sporozoite rate and entomological inoculation rate}

The Enzyme Linked Immunosorbent Assay (ELISA) was used to detect Plasmodium falciparum circumsporozoites proteins (CSP) in malaria parasite-infected female Anopheles mosquitoes (Wirtz et al., 1987). The Entomological Inoculation Rate (EIR) was calculated from estimates of bites per person and multiplying by the sporozoite rates per night. The annual EIR was then determined by multiplying the mean number of human bites per night by the sporozoite rate and by 365 days

\section{Larval search}

Breeding sites were mapped using geographical positioning system (GPS) machines. Larvae were collected using a standard white enamel dipper $(250 \mathrm{ml})$ attached to a wooden handle of an appropriate length as described by Service (1971). Collected larvae were later brought to the field laboratory and identified based on external morphological features (Gillies \& de Meillon, 1968).

\section{Meteorological data}

Weekly rainy data were recorded at the centre point weather station in the village.

\section{Data analysis}

Statistical analysis was carried out using SPSS 16.0 for Windows (SPSS Inc, Chicago, USA). Proportions of categorical data were reported and Chi-squared test was used to determine heterogeneity of data collected in different seasons. Statistical significance was set at $5 \%$ level.

\section{Ethical considerations}

Ethical clearance to conduct the study was sought from the Kilimanjaro Christian Medical Centre Ethical Clearance Committee and the Tanzania National Institute for Medical Research (NIMR/HQ/R.8a/Vol. IX/759). Informed consent was obtained from head of the family on behalf of the occupants.

\section{Results}

A total of 110,357 adult female mosquitoes (27.6\% anophelines and $72.4 \%$ culicines) belonging to three genera Anopheles, Culex and Mansonia were collected. The Anopheles genus was represented by, An. gambiae s.l, An. pharoensis, An. coustani, An. funestus, An. marshallii and An. maculpalpis. An. gambiae s.l. accounted $25 \%$ for of the total female mosquito collected (Table 1). On average 82.1 mosquitoes were caught per night per trap with a mean of 22.6 Anopheles mosquitoes per trap per night. Culex was represented by Culex quinquefasciatus ( $\mathrm{N}=77098)$, and Culex unnivittatus ( $\mathrm{N}=4047)$. Mansonia was represented by Mansonia uniformis $(\mathrm{N}=33)$ and Mansonia africana $(\mathrm{N}=11)$. 
Table 1: Anopheles mosquito species composition, mean number collected and sporozoite infectivity rate in Magugu

\begin{tabular}{lllll}
\hline Species & $\begin{array}{l}\text { No. } \\
\text { female } \\
\text { collected }\end{array}$ & $\begin{array}{l}\text { Mean number per } \\
\text { trap }\end{array}$ & No. dissected & No. infected \\
\hline An. gambiae s.l. & 27557 & 19.5 & 8973 & 2 \\
An. funestus & 290 & 0.2 & 100 & 0 \\
An. pharoensis & 773 & 0.6 & 300 & 0 \\
An. coustani & 499 & 0.4 & 100 & 0 \\
An. maculipalpis & 45 & 0.03 & 25 & 0 \\
An. marshallii & 4 & 0.002 & 2 & 0 \\
\hline
\end{tabular}

A total of 480 mosquitoes morphologically identified as An. gambiae complex were analysed by PCR in order to differentiate different sibling species. The assay identified $A n$. arabiensis as the only member of the An. gambiae complex in the collected samples. However, $39.7 \%$ per plate of the species could not be identified.

Overall, number of mosquitoes trapped increased from 19,700 in the dry season to 95,656 in the wet season (Figure 1). During the wet season the mean catch per trap was 99 mosquitoes, of which average Anopheles mosquitoes were 30.6 per trap. In the dry season, mean catch per trap was 44.7 mosquitoes, of which average Anopheles mosquitoes were 5.1 per trap. The percentage of collection per species correlated with the increasing mean rainfall. An. gambiae s.l. collection was higher in all both seasons, being highest in November/December 2008. Relatively fewer An. funestus were collected, with a high peak in $(30.6 \% ; 120 / 392)$ in May 2009. Likewise, for An. coustani and An. pharoensis highest peak species collection was in May 2009 at 43.6\% (232/531) and 44.6\% (381/853), respectively.

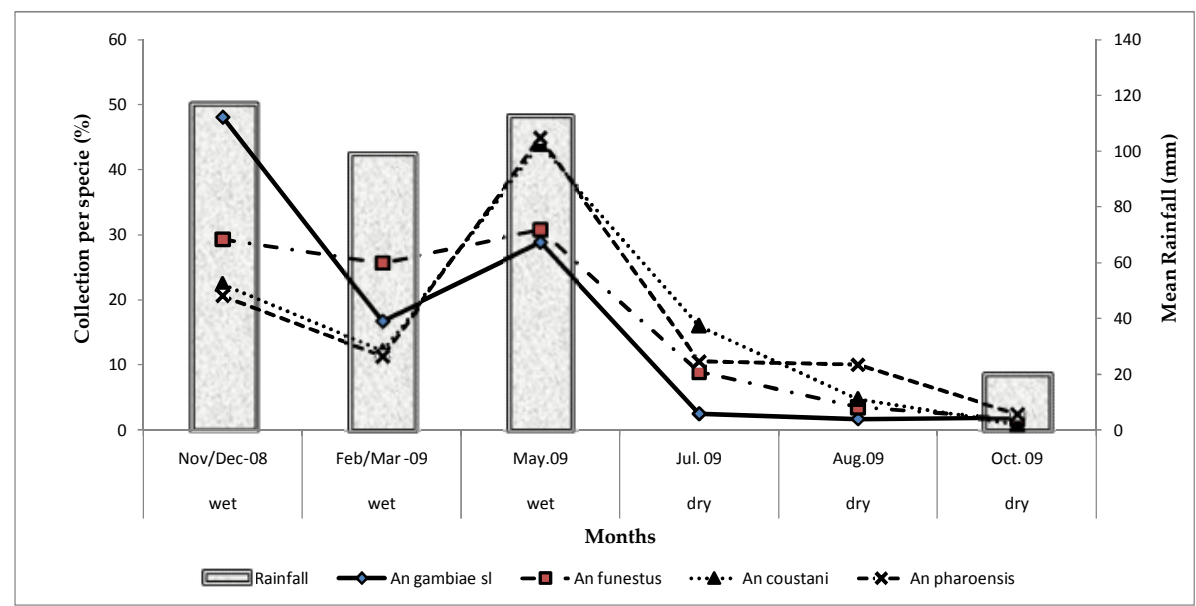

Figure 1: Variation of Anopheles mosquito trapped in dry and wet season

Blood meal analysis on mosquito blood meal source showed a higher human enzymatic reaction among An. gambiae s.1. (63.5\%) followed by An. funestus (42.9\%). Bovine enzymatic reaction was higher among An. coustani (73.7\%) followed by the An. pharoensis (66.7\%). Mixed blood meal, which composed of human+bovine, human+goat, bovine+ goat, dog+bovine was observed in An. gambiae, An. pharoensis and An. coustani.

Out of the 29,168 female Anopheles mosquitoes collected, 10,000 were processed for $P$. falciparum circumsporozoite protein ELISA antigen test. The selection was based on the 
having representativeness of the caught mosquitoes from different areas in the village and different seasons. Only two An. arabiensis were found to be infected and its EIR was 0.51 infectious bites per person per year.

Table 2: Blood meal preference of mosquitoes in Magugu

\begin{tabular}{|c|c|c|c|c|c|c|c|}
\hline \multicolumn{8}{|c|}{ Blood meal source as per Enzymatic Test Results } \\
\hline $\begin{array}{l}\text { Mosquito } \\
\text { species }\end{array}$ & $\begin{array}{l}\text { Human } \\
(\mathrm{N}=113)\end{array}$ & $\begin{array}{l}\text { Bovine } \\
(\mathrm{N}=66)\end{array}$ & $\begin{array}{l}\text { Goat } \\
(\mathrm{N}=22)\end{array}$ & $\operatorname{Dog}(\mathrm{N}=10)$ & $\begin{array}{l}\text { Chicken } \\
(\mathrm{N}=5)\end{array}$ & $\begin{array}{l}\text { Mixed } \\
(\mathrm{N}=10) \\
\end{array}$ & P-value \\
\hline $\begin{array}{l}\text { An. gambiae s.l. } \\
\%(\mathrm{n})\end{array}$ & $\begin{array}{r}63.5 \% \\
(101)\end{array}$ & $\begin{array}{r}15.7 \% \\
(25)\end{array}$ & $\begin{array}{l}8.8 \% \\
(14)\end{array}$ & $\begin{array}{r}5.0 \% \\
(8)\end{array}$ & $\begin{array}{r}2.5 \% \\
(4)\end{array}$ & $\begin{array}{r}4.4 \% \\
(7)\end{array}$ & $<0.0001$ \\
\hline $\begin{array}{l}\text { An. funestus } \\
\% \text { (n) }\end{array}$ & $\begin{array}{r}42.9 \% \\
(6)\end{array}$ & $\begin{array}{r}35.7 \% \\
(5)\end{array}$ & $\begin{array}{r}14.3 \% \\
(2)\end{array}$ & 0 & 0 & $\begin{array}{r}7.1 \% \\
(1)\end{array}$ & 0.859 \\
\hline $\begin{array}{l}\text { An. pharoensis } \\
\% \text { (n) }\end{array}$ & $\begin{array}{r}12.1 \% \\
(4)\end{array}$ & $\begin{array}{r}66.7 \% \\
(22)\end{array}$ & $\begin{array}{r}12.1 \% \\
(4)\end{array}$ & $\begin{array}{r}3.0 \% \\
(1)\end{array}$ & 0 & $\begin{array}{r}20 \% \\
(2)\end{array}$ & $<0.0001$ \\
\hline $\begin{array}{l}\text { An. coustani } \\
\% \text { (n) }\end{array}$ & $\begin{array}{r}10.5 \% \\
(2)\end{array}$ & $\begin{array}{r}73.7 \% \\
\quad(14)\end{array}$ & $\begin{array}{r}5.3 \% \\
(1)\end{array}$ & $\begin{array}{r}5.3 \% \\
(1)\end{array}$ & $\begin{array}{r}5.3 \% \\
(1)\end{array}$ & 0 & $<0.0001$ \\
\hline
\end{tabular}

The mosquito larvae were collected once at the beginning of the study in October 2008. Overall, Culex larvae were more abundant, 82\% (2015/2457) compared to Anopheles larvae, $17.9 \%$ (442/2457). At village level, a significant difference was observed in different breeding sites in relation to the various types of mosquito larvae collected. Culex larvae were more abundant, 36.6\% (739/2015) in Gichameda A compared to 33.8\% (683/2015) in Gichameda B, 14.6\% (294/2015) in Kinambichi and 14.8\% (299/2015) in Madibira. Anopheles larvae were reported to be more abundant, 73.9\% (327/442) in Gichameda B compared to 12.4\% (55/442)in Madibira, 9.3\% (41/442) in Kinambichi and 4.3\% (19/442) in Gichameda A $\left(\chi^{2}=13.75, P=0.00021\right)$. In addition, 20 breeding sites were identified in Gichameda A, 15 breeding sites in Kinambichi, 12 breeding sites in Gichameda B and 11 breeding sites in Madibira.

\section{Discussion}

Knowledge on the abundance and distribution of malaria vectors in an area is important for the design and implementation of malaria control strategies. Like in our study, studies elsewhere in Tanzania have reported that An. gambiae s.l. and An. funestus, are the most important malaria vectors (Davis et al., 1995; Haji et al., 1996; Ijumba et al., 2002; Mwanziva et al., 2008; Kigadye et al., 2010). Results from PCR assays indicate that only An. arabiensis exists in this area during both wet and dry seasons. An. funestus which breeds in clear shallow water, weedy side of streams and swampy areas were found in low numbers in the area. The low abundance of An. funestus could be explained by the absence of typical breeding habitats in the area.

The seasonal variation in mosquito abundance indicates its dependence on the rain. The exophily of An. arabiensis could have an effect on the numbers of mosquitoes caught as traps used were of indoor type. This behavioural pattern was also reported in a study 
conducted in the area by Smith, (1962) and also in other places in northern Tanzania (Kulkarni et al., 2006; Mahande et al., 2007; Kweka et al., 2008).

Though CSP- ELISA was negative for identified An. pharoensis and An. coustani, the blood meal test showed that An. pharoensis as well as An. coustani had fed on a human which indicates their potential to transmit malaria. In a study conducted in Kenya to map the distribution of malaria vectors (Okara et al., 2010), An. pharoensis was defined as one of the important malaria vectors. A similar anthropophilic tendency of An. coustani has been reported from Zambia (Fornadel et al., 2010a).

Sporozoite rates depicts exposure rate of an individual to infected mosquitoes and is an important parameter for defining transmission intensity and disease endemicity in an area. The CSP-ELISA results show that the intensity of malaria transmission in this area is low. The low level of endemicity makes this area suitable for malaria control and elimination. There has been no larviciding or indoor residual spraying activities in the area during recent years and therefore, the observed EIR could be attributed to other factors.

The blood meal analyses indicate various host preferences already reported by various workers (Lefevre et al., 2009; Mahande et al., 2007; Shililu et al. 2004). The results indicate that malaria vectors in Magugu are both anthropophagic and zoophagic. Although it is known that An. arabiensis is known to be strongly zoophagic (Habtewold et al., 2001, 2004; Muriu et al., 2008), but this was not the case in our study where the results suggests a relatively high anthropophagic tendency. Similar observations have been reported by other studies (Tirados et al., 2006; Kasili et al., 2009; Fornadel et al., 2010b).

The reasons for low density of An. funestus in the areas could not be established. An. funestus exists as complex species, and specific species were not established in this study. The mosquito is known to breed in rice fields (Ijumba et al.,2002; Mutero et al., 2004; Muturi et al., 2006), which are common in the study area. An. funestus is an important malaria vector in Tanzania and is known for its high human blood index (Temu et al., 2007) and endophilic and anthropophilic behaviour (Mboera et al., 1998). However, like in our study, in Madagascar An funestus was observed to be more zoophilic than anthropophillic (Rajaonarivelo et al., 2004). Multiple blood meal sources 3.6\% were noted in An. gambiae, An. pharoensis and An. funestus. This is mostly attributed to the increased demand of energy above the normal level during the oocytes development (Ramasamy et al., 2000) and adaptation to this phenomenon expresses their potentiality to malaria parasite transmission capability (McCall et al., 2001).

Comparatively low numbers of adult An. gambiae complex as compared to abundant larvae could be due to washout by rain floods. A similar picture was reported by studies conducted in Kenya, Mali, Gambia and in Southern Africa (Klinkenberg et al., 2003; Paaijmans et al., 2007; Mabaso et al., 2007; Majambere et al., 2010). However, it expected that not all larvae would hatch to pupae and not all pupae emerge as adults.

In conclusion, this study has shown that An. arabiensis is the major malaria vector in Magugu area and that the mosquito is to a large extent anthropoghagic. Only two An. arabiensis mosquitoes were found positive for circumsporozoites. This EIR was considered to be relatively low, indicating that malaria transmission in this area is low. The variability in mosquito blood meal shows availability of variety of preferred blood meal choices and impact of other factors inhibiting mosquito-human host contact. This study has provided information considered useful in the mapping of the vector distribution and population structure in the country. Such information is considered to important for planning malaria control interventions. 


\section{Acknowledgements}

The authors acknowledges the support of the Biotechnology Laboratory at the Kilimanjaro Clinical Research Institute (KCRI) in Moshi, Ifakara Health Institute, Morogoro and the National Institute for Medical Research at Amani Centre in Muheza, for devoting their time to work on samples and perform data analysis. Martin Frank, Paul Mrema, Joseph Bayo, Collins Mweresa, Silas Otieno, Benard Batengana, Omary Mpili, Heri Bakari, Josephine Nyongole, Deus Ishengoma, Sudi Iwitiho, Alex John, Deogratias Roman, Arnold Ndaro and Margret Kivuyo are acknowledged for their support in the field and laboratory work. We are grateful for the contribution of village leaders and village communities to this project. Special thanks to Teun Bousema for full support from the start of the work. The study received support from KCRI, Kilimanjaro Christian Medical College and African Malaria Network Trust.

\section{References}

Black, R.E., Morris, S.S. \& Bryce, J. (2003) Where and why are 10 million children dying every year? Lancet 361 (9376), 2226-2234.

Bray, R.S., Gill, G.S. \& Killick-Kendrick, R. (1984) Current and possible future technique for the identification of bloodmeals of vector haematophagous arthropods. World Health Organization, WHO/VBC/84.905.

Carter, R. \& Mendis, K.N. (2002) Evolutionary and Historical Aspects of the Burden of Malaria. Clinical Microbiology 15, 564-594.

Davis, J.R., Hall, T., Chee, E.M., Majala, A., Minjas, J., \& Shiff, C.J. (1995) Comparison of sampling anopheline mosquitoes by light-trap and human-bait collections indoors at Bagamoyo, Tanzania. Medical and Veterinary Entomology 9, 249-255.

Drakeley, C., Schellenberg, D., Kihonda, J., Sousa, C.A., Arez, A.P., Lopes, D., Lines,J., Mshinda, H., Lengeler, C., Armstrong, S.J., Tanner, M., \& Alonso, P. (2003) An estimation of the entomological inoculation rate for Ifakara: a semi-urban area in a region of intense malaria transmission in Tanzania. Tropical Medicine E International Health 8, 767-774.

Fornadel, C.M., Norris, L.C., Franco, V. \& Norris, D. E. (2010a) Unexpected anthropophily in the potential secondary malaria vectors Anopheles coustani s.l. and Anopheles squamosus in Macha, Zambia. Vector-Borne and Zoonotic Diseases. doi:10.1089/vbz.2010.0082.

Fornadel, C.M., Norris, L.C., Glass, G.E. \& Norris, D.E. (2010b) Analysis of Anopheles arabiensis blood feeding behavior in southern Zambia during the two years after introduction of insecticide-treated bed nets. American Journal of Tropical Medicine and Hygiene 83, 848-853.

Gillies, M.T. \& Coetzee, M. (1987) A Supplement to the Anopheline of Africa South of Sahara (Afrotrpical region). Publication of the South African Institute of Medical Research 55, 1- 143.

Gillies, T.M. \& de Meillon, D.B. (1968) The Anopheles of Africa South of Sahara (Ethiopian Zoogeographic Region). The South African Institute for Medical Research, Johannesburg. Publication No.54. 
Githeko, A.K., Service, M.W., Mbogo, C.M., Atiel, F.K. \& Juma, F.O. (1993) Plasmodium falciparum sporozoite and entomological inoculation rates in the Ahero irrigation scheme and the Miwani sugar-belt in western Kenya. Annals of Tropical Medicine and Parasitology 87, 379-391.

Habtewold, T., Prior, A., Torr, S.J., \& Gibson, G. (2004) Could insecticide-treated cattle reduce Afrotropical malaria transmission? Effects of deltamethrin-treated Zebu on Anopheles arabiensis behaviour and survival in Ethiopia. Medical and Veterinary Entomology 18, 408-417.

Habtewold, T., Walker, A. R., Curtis, C. F., Osir, E. O., \& Thapa, N. (2001) The feeding behaviour and Plasmodium infection of Anopheles mosquitoes in southern Ethiopia in relation to use of insecticide-treated livestock for malaria control. Transactions of the Royal Society of Tropical Medicine and Hygiene 95, 584-586.

Haji, H., Smith, T., Charlwood, J.D., \& Meuwissen, J.H. (1996) Absence of relationships between selected human factors and natural infectivity of Plasmodium falciparum to mosquitoes in an area of high transmission. Parasitology 113, 425-431.

Ijumba, J.N., Mosha, F.W., \& Lindsay, S.W. (2002) Malaria transmission risk variations derived from different agricultural practices in an irrigated area of northern Tanzania. Medical and Veterinary Entomology 16, 28-38.

Kasili, S., Odemba, N., Ngere, F. G., Kamanza, J. B., Muema, A. M., \& Kutima, H. L. (2009) Entomological assessment of the potential for malaria transmission in Kibera slum of Nairobi, Kenya Journal of Vector Borne Diseases 46, 273-279.

Kigadye, E.S.P, Nkwengulila, G., Magesa, S.M. \& Abdulla, S. (2010) Diversity, spatial and temporal abundance of Anopheles gambiae complex in the Rufiji River basin, south-eastern Tanzania. Tanzania Journal of Health Research 12, 68-72.

Killeen, G.F., McKenzie, F.E., Foy, B.D., Schieffelin, C., Billingsley, P.F., \& Beier, J.C. (2000) A simplified model for predicting malaria entomologic inoculation rates based on entomologic and parasitologic parameters relevant to control. American Journal of Tropical Medicine and Hygiene 62, 535-544.

Klinkenberg, E., Takken, W., Huibers, F., \& Toure, Y.T. (2003) The phenology of malaria mosquitoes in irrigated rice fields in Mali. Acta Tropica 85, 71-82.

Kulkarni, M.A., Kweka, E., Nyale, E., Lyatuu, E., Mosha, F.W., Chandramohan, D., Rau, M.E., \& Drakeley, C. (2006) Entomological evaluation of malaria vectors at different altitudes in Hai district, north-eastern Tanzania. Journal of Medical Entomology 43, 580-588.

Kweka, E.J., Nkya, W.M., Mahande, A.M., Assenga, C., Mosha, F.W., Lyatuu, E.E., Massenga, C.P., Nyale, E.M., Mwakalinga, S.B., \& Lowassa, A. (2008) Mosquito abundance, bed net coverage and other factors associated with variations in sporozoite infectivity rates in four villages of rural Tanzania. Malaria Journal 7, 59.

Kwiatkowski, D.P. (2005) How malaria has affected the human genome and what human genetics can teach us about malaria. American Journal of Human Genetics 77, 171-190.

Lefevre, T., Gouagna, L.C., Dabire, K.R., Elguero, E., Fontenille, D., Renaud, F., Costantini, C., \& Thomas, F. (2009) Beyond nature and nurture: phenotypic plasticity in bloodfeeding behavior of Anopheles gambiae s.s. when humans are not readily accessible. American Journal of Tropical Medicine and Hygiene 81, 1023-1029.

Mabaso, M. L., Kleinschmidt, I., Sharp, B., \& Smith, T. (2007) El Nino Southern Oscillation (ENSO) and annual malaria incidence in Southern Africa. Transactions of the Royal Society of Tropical Medicine and Hygiene 101, 326-330. 
Magesa, S.M., Wilkes, T.J., Mnzava, A.E., Njunwa, K.J., Myamba, J., Kivuyo, M.D., Hill, N., Lines, J.D. \& Curtis, C.F. 1991) Trial of pyrethroid impregnated bednets in an area of Tanzania holoendemic for malaria. Part 2. Effects on the malaria vector population. Acta Tropica 49, 97-108.

Mahande, A., Mosha, F., Mahande, J. \& Kweka, E. (2007) Feeding and resting behaviour of malaria vector, Anopheles arabiensis with reference to zooprophylaxis. Malaria Journal 6, 100.

Majambere, S., Pinder, M., Fillinger, U., Ameh, D., Conway, D. J., Green, C., Jeffries, D., Jawara, M., Milligan, P. J., Hutchinson, R., \& Lindsay, S. W. (2010) Is mosquito larval source management appropriate for reducing malaria in areas of extensive flooding in The Gambia? A cross-over intervention trial. American Journal of Tropical Medicine and Hygiene 82, 176-184.

Malima, R.C. (1999) Sporozoite Rates and Species Identify of Mosquitoes Collected from Highland and Lowland Tanzania. MSc. Dissertation, University of London. 53 pp.

Mboera, L.E.G, Senkoro, K. P., Mayala, B. K., Rumisha, S. F., Rwegoshora, R. T., Mlozi, M. R., \& Shayo, E. H. (2010) Spatio-temporal variation in malaria transmission intensity in five agro-ecosystems in Mvomero district, Tanzania. Geospatial Health 4, 167-178.

Mboera, L.E.G. (2000) Fifty Years of Health Research in Tanzania (1949 - 1999). Annotated Bibliography, DUP (1996) Ltd., 373pp

Mboera, L.E.G., Kihonda, J., Braks, M.A.H. \& Knols, B.G.J. (1998) Influence of Centers for Disease Control light trap position, relative to a human-baited bed net, on catches of Anopheles gambiae and Culex quinquefasciatus in Tanzania. American Journal of Tropical Medicine and Hygiene 59, 595-596.

Mboera, L.E.G., Pedersen, E.M., Salum, F.M., Msuya, F.H. \& Sambu, E.Z. (1997)Transmission of malaria and bancroftian filariasis in Magoda area, north-east Tanzana. Malaria and Infectious Diseases in Africa 7, 61-67.

McCall, P.J., Mosha, F.W., Njunwa, K.J., \& Sherlock, K. (2001) Evidence for memorized site-fidelity in Anopheles arabiensis. Transactions of the Royal Society of Tropical Medicine and Hygiene 95, 587-590.

Mnzava, A.E. \& Kilama, W.L. (1986) Observations on the distribution of the Anopheles gambiae complex in Tanzania. Acta Tropica 43, 277-282.

MoHSW (2008) Medium Term Malaria Strategic Plan, Ministry of Health and Social Welfare, Dar es Salaam, Tanzania.

Muriu, S. M., Muturi, E. J., Shililu, J. I., Mbogo, C. M., Mwangangi, J. M., Jacob, B. G., Irungu, L. W., Mukabana, R. W., Githure, J. I., \& Novak, R. J. (2008) Host choice and multiple blood feeding behaviour of malaria vectors and other anophelines in Mwea rice scheme, Kenya. Malaria Journal 7, p. 43.

Mutero, C. M., Kabutha, C., Kimani, V., Kabuage, L., Gitau, G., Ssennyonga, J., Githure, J., Muthami, L., Kaida, A., Musyoka, L., Kiarie, E., \& Oganda, M. (2004) A transdisciplinary perspective on the links between malaria and agroecosystems in Kenya. Acta Tropica 89, 171-186.

Muturi, E. J., Muriu, S., Shililu, J., Mwangangi, J., Jacob, B. G., Mbogo, C., Githure, J., \& Novak, R. J. (2008) Effect of rice cultivation on malaria transmission in central Kenya. American Journal of Tropical Medicine and Hygiene 78, 270-275.

Mwanziva, C., Shekalaghe, S., Ndaro, A., Mengerink, B., Megiroo, S., Mosha, F., Sauerwein, R., Drakeley, C., Gosling, R., \& Bousema, T. (2008) Overuse of 
artemisinin-combination therapy in Mto wa Mbu (river of mosquitoes), an area misinterpreted as high endemic for malaria. Malaria Journal 7, 232.

Okara, R.M., Sinka, M.E., Minakawa, N., Mbogo, C.M., Hay, S.I., \& Snow, R.W. (2010) Distribution of the main malaria vectors in Kenya. Malaria Journal 9, 69.

Paaijmans, K.P., Wandago, M.O., Githeko, A.K., \& Takken, W. (2007) Unexpected high losses of Anopheles gambiae larvae due to rainfall. PLOS ONE 2, e1146.

Rajaonarivelo, V., Le, G. G., Cot, M., \& Brutus, L. (2004) Anopheles and malaria transmission in Ambohimena, a village in the Occidental fringe of Madagascar Highlands. Parasite 11, 75-82.

Ramasamy, M.S., Srikrishnaraj, K.A., Hadjirin, N., Perera, S., \& Ramasamy, R. (2000) Physiological aspects of multiple blood feeding in the malaria vector Anopheles tessellates. Journal of Insect Physiology 46, 1051-1059.

Scott, J.A., Brogdon, W.G., \& Collins, F.H. (1993) Identification of single specimens of the Anopheles gambiae complex by the polymerase chain reaction. American Journal of Tropical Medicine and Hygiene 49, 520-529.

Service, M. W. (1971) Studies on sampling larval populations of the Anopheles gambiae complex. Bulletin of the World Health Organization 45, 169-180.

Shiff, C.J., Minjas, J.N., Hall, T., Hunt, R.H., Lyimo, S., \& Davis, J.R. (1995) Malaria infection potential of anopheline mosquitoes sampled by light trapping indoors in coastal Tanzanian villages. Medical and Veterinary Entomology 9, 256-262.

Shililu, J., Ghebremeskel, T., Seulu, F., Mengistu, S., Fekadu, H., Zerom, M., Asmelash, G. E., Sintasath, D., Mbogo, C., Githure, J., Brantly, E., Beier, J. C., \& Novak, R. J. (2004) Seasonal abundance, vector behavior, and malaria parasite transmission in Eritrea. Journal of the American Mosquito Control Association 20, 155-164.

Smith, A. (1962) Malaria in the Taveta area of Kenya and Tanganyika. II. Entomological findings three years after the spraying period. East African Medical Journal 39, 553564.

Temu, E.A., Minjas, J.N., Tuno, N., Kawada, H., \& Takagi, M. (2007) Identification of four members of the Anopheles funestus (Diptera: Culicidae) group and their role in Plasmodium falciparum transmission in Bagamoyo coastal Tanzania. Acta Tropica $102,119-25$.

Tirados, I., Costantini, C., Gibson, G., \& Torr, S.J. (2006) Blood-feeding behaviour of the malarial mosquito Anopheles arabiensis: implications for vector control. Medical and Veterinary Entomology 20, 425-437.

Van Rensburg, A.J., Hunt, R.H., Koekemoer, L.L., Coetzee, M., Shiff, C.J., \& Minjas, J. (1996) The polymerase chain reaction method as a tool for identifying members of the Anopheles gambiae complex (Diptera: Culicidae) in northeastern Tanzania. Journal of the American Mosquito Control Association 12, 271-274.

White, G.B. (1974) Anopheles gambiae complex and disease transmission in Africa. Transactions of the Royal Society of Tropical Medicine and Hygiene 68, 278-301.

WHO (2006) The Africa Malaria Report. 2006. Regional Offices for Africa and the Mediterranean, World Health Organization.

Wilkes, T.J., Matola, Y.G. \& Charlwood, J.D. (1996) Anopheles rivulorum, a vector of human malaria in Africa. Medical and Veterinary Entomology 10, 108-110.

Wirtz, R.A., Burkot, T.R., Graves, P.M., \& Andre, R.G. (1987) Field evaluation of enzymelinked immunosorbent assays for Plasmodium falciparum and Plasmodium vivax 
sporozoites in mosquitoes (Diptera: Culicidae) from Papua New Guinea. Journal of Medical Entomology 24, 433-437. 